\title{
Conservation of Italian Autochthonous Domestic Pigeon Breeds
}

\section{Antonio Pizzuti Piccoli}

Natura per Tutti Onlus Organization, - Via Monteroni n¹265, 00055 Ladispoli (RM) Italy.

\begin{abstract}
In this work it is proposed an analysis of the conservation status of Italian autochthonous domestic pigeon breeds. As like as other domestic species, the domestic pigeon is undergoing a rapid decline. In Italy the pigeon breeding is an ancient practice anterior to the Roman period. Actually we have 11 autochthonous breeds, here described in their mainly characteristics, and for everyone is proposed the population size and the perspective of conservation for the future. An important and fundamental impulse to the conservation of these breeds has been given by the Italian Pigeon Breeders Federation - FIAC and its numerous members, which have preserved the biodiversity heritage of the domestic pigeon in Italy. Of the Italian autochthonous breeds, only three are considered not at risk, while the other are in the range size for the breeds considered threatened. Two breeds, the Rondone frill and the Parma Occhialone pigeon are now present with numbers that classify them in the "critical" category. For the Rondone frill a numerical increase program is being developed, for the Parma Occhialone pigeon the FIAC has activated a recovery and diffusion program.
\end{abstract}

To guarantee a future for biodiversity of this interesting domestic species in Italy, will be necessary to encourage the breeding of these Italian autochthonous domestic pigeons.

Keywords - pigeon breeds, conservation status, domestic pigeon, Italy, population size.

\section{INTRODUCTION}

It has been estimated that since domestication, in the last 12,000 years, over 7616 breeds have been selected by 30 species of domestic animals. In the past hundred years, around $22 \%$ of known animal breeds have become extinct and another $27 \%$ have varying degrees of risk. It is also reported that approximately two breeds of poultry and livestock are lost every week (Grunenfelder, 2001; Rischkowsky \& Pilling, 2007; Bigi \& Zanon, 2008).

The autochthonous domestic breeds have been an integral part of the livelihoods and traditions of different communities over the years and the loss of one defined race is a loss of the cultural identity and heritage of that community (Belew et al., 2016). Losing these breeds is like losing a comprehensive insurance policy against future food security threats (Shah et al., 2016). The indiscriminate crossing between exotic breeds and indigenous animals was judged to be the main cause of the losses, as well as the risk for the existing breeds. It may be too late for many livestock and poultry breeds in Europe; also in developing countries the loss of diversity and indigenous animals is present, even if it is less high. The continued import of highly productive animals from developed countries is believed to be the most significant threat to domestic animal diversity in developing countries (Hanotte \& Jianlin 2006)
In this context fits the domestic pigeon, which, like other domesticated species, is undergoing a rapid decline. In this work, the native domestic breeds of pigeons in Italy are described; the Author wants to define their status and perspective for future protection from extinction.

\section{THE BREEDING OF PIGEONS IN ITALY}

The domestic pigeon is a direct descendant of the Rock Pigeon Columba livia Gmelin 1789, a wild species native to Europe, North Africa, the Middle East, and South Asia. The species was probably domesticated at several times and places. Archeological evidence points to human use of pigeons as a food source as early as the Pleistocene ( 10,000 years ago) in the Fertile Crescent, although whether this entailed domestication is not known. Ancient Egyptians began using pigeons for ceremonial and culinary purposes at least 4000 years ago, and later as harbingers of the progress of the Nile's annual flood. Ancestors of some modern breeds were probably developed between 2000 and 860 years ago. The geographic centers of biodiversity for pigeon appear to be the Middle East and South Asia (modern India and Pakistan); from these geographical areas the domestic pigeons were then spread all over the world (Giusti, 1996). 
In Europe, the popularity of the pigeon breeding raised markedly in the 17th Century. With the publication of the works of Charles Darwin "The origin of the species through natural selection" and "The variations of plants and animals in the domestic state", which took place around in the mid-1800s, we can point at the born of the modern selective pigeon breeding. The theses supported by Darwin found confirmation of their validity and were rapidly implemented in pigeon breeding, leading to the creation of numerous new varieties. The working material was supplied, as well as by the breeds already existing in Europe, by new breeds that were imported from the eastern colonies especially in England-earth, then the center of a vast empire. (Pizzuti Piccoli, 2016)

In all Europe about 1050 of pigeon breeds are present today; of these many are endangered (AA.VV., 2018).

In Italy probably the breeding and use of the pigeon was introduced by the Greeks to Magna Grecia. From Sicily the interest in breeding spread rapidly to Rome and Italy, especially in the area around Modena which constituted an important Roman colony for its geographical position. Varrone Latino (1st century B.C.) in his works deals with details of the breeding of pigeons, reporting that in his day a couple used to be sold for 1,000 sesterces and that there were pigeon lofts with 5,000 animals. Columella (1st century A.D.) teaches how to build a pigeon loft how to breed pigeons. (Calzecchi Onesti, 1977; Traglia A., 1996).

The historian Plinio in his "Historia naturalis," as well as Frontino, tell that in the year 43 B.C., when Modena was besieged by Marco Antonio, the connections between Decio Bruto, besieged in the city, and the encampment of Consul Irzio were possible thanks to messengers pigeons. (Malossini, 2011)

The Italian Ulisse Aldrovandi, from Bologna, was the first in Europe to write, around 1600, a scientific treatise on the breeds of pigeons existing in his time.

In Italy, in the city of Modena, the "game of flying" of the Triganini pigeons had been widespread since time immemorial. Many testimonies have been handed down about it, the most famous of which is that, dating back to 1614, by Alessandro Tassoni who, in his heroic poem "La secchia rapita", speaks of the people dedicated to this sport, that were called "triganieri" (Puliatti, 1989)

The period of greatest diffusion of this custom was at the beginning of the $1800 \mathrm{~s}$, when many people, belonging to every social class, spent most of the day on the roofs, taken as they were from the passion for this game. (Polacci, 1978)
Today, Italian pigeon breeders are organized in many local associations and, at a national level, in a Federation, the Italian Federation of Pigeon Breeders (acronym FIAC).

The F.I.A.C. was founded in 1977 and today brings together 27 Italian Associations of pigeon breeders and 12 Groups of breeders specialized on one or more particular breed. Every year the FIAC organizes the National Pigeons Exposition, a national show where it is possible to admire the best specimens bred in Italian lofts.

Despite this passion, we live the great problem of the conservation of biodiversity of domestic pigeon breeds.

In recent decades one of the greatest problems we face is the conservation of all breeds of domestic pigeons, which risk disappearing forever. Some breeds have already disappeared in Europe and others are reduced to a minimum; all these domestic varieties will live as long as there are fans that will breed them with many sacrifices and a lot of passion. (Pizzuti Piccoli, 2011)

\section{ITALIAN AUTOCHTHONOUS BREEDS}

Today in Italy 10 pigeon breeds are officially recognized as Italian breeds. For each breed, the FIAC has, from years, established a standard with breed characteristics.

The breed standard is the more possible accurate description of physical and behavioral characteristics that an "ideal" specimen of a given animal breed should possess; therefore it serves as a guide for breeders to determine which distinctive features to privilege in the selection.

In the Standard the breed is described in its general aspect and in the details of the individual anatomical parts. The possible variants are listed (for example the various colors of the plumage), any points of particular value in the specimen that should be enhanced for the reproductive selection are listed. The Standard also report the inadmissible defects identified, which lead (or should lead) to the exclusion from reproduction, in order to maintain the morphological homogeneity of the breed and exclude unwanted mutations that can lead, for example, to health problems.

A French breed, the Roman pigeon, is considered to be a descendant of an Italian breed perfected in France.

In addition to the official breeds, of which the FIAC is the custodian of the standards and, above all, has guaranteed conservation up to the present day, there are many local breeds that have disappeared over time; is this the case of the Parma Occhialone pigeon, first considered extinct and then "rediscovered" in Sicily, treated separately below. 


\section{The Piacentino pigeon}

The first evidence of Piacentino pigeon (Fig.1) dates back to the nineteenth century in Emilia Romagna, precisely in the neighboring countryside of Piacenza, it probably derives by crossing large indigenous pigeons, Roman and Bagdad pigeons. It is a large-sized pigeon, of robust constitution with a wide chest and horizontal position. The minimum weight for adults varies from 850 grams for females to 900 grams for males. The length from the tip of the beak to the end of the tail varies from 34 to 36 centimeters, while its height varies from 31 to 33 centimeters. Piacentino pigeons have a large, smooth, convex and well rounded head in all its set; it must form a continuous and rounded line that starts from the tip of the beak to arrive harmoniously at the junction of the neck with the neck. It has large eyes with dark iris in the white coloration (vetch eye), orange red (rooster eye) in all the other colorations. The rings of the eyes appear broad, not excessively protruding, nor too fleshy with a bright red color (cardinal red). Medium length beak often joins to the forehead without restriction (no stapling). The beak is pink in color in the white pigeons and more or less light horn in the remaining colorations. The wattles are white, wide and well extended, but smooth and not too pronounced; they must not break the continuous line of the profile between the forehead and the beak. Well carved throat with no hint of dewlap. Strong, medium-length neck, wide at the attachment with the chest, it reduces harmoniously up to the throat. It has wide, prominent, rounded chest, deep but not visible sternum. Wide back, medium length carried horizontally. It has large, tightly fitting wing shields that cover the back. Feathers well closed, lying above the tail and slightly shorter than it. Tail of medium length, compact, slightly raised, it goes beyond the end of the flight feathers by 2 or 3 centimeters. Sturdy, mediumlength legs, well spaced from each other, with slightly angled profile. It has thighs clearly visible, fingers with nails of the same color as the beak (AA.VV., 1999).

\section{The Romagnol pigeon}

Romagnol (Fig.2) was already selected in the second half of the 19th century, starting from big pigeons bred for centuries in the farms and colonies of the provinces of Romagna and Bolognese. The name Romagnol is attributed to this pigeon by prof. Alessandro Ghigi in 1898, given its diffusion in the districts of Romagna. Romagnol is a big size pigeon, with prominent and well rounded wide chest. It has a horizontal standing and an average high position on the legs that are characterized by the presence of well-developed spurs and slippers. The minimum weight in adults is 800 grams for females and 900 for males. The pigeon has a height from 31 to 32 centimeters and his length (from the tip of the beak to the end of the tail) is from 32 to $34 \mathrm{~cm}$.

The head is smooth and well rounded without interruptions or flattening, it has a rounded forehead that forms with the beak an obtuse angle. The beak is of medium length rather carried almost horizontal. The wattles are smooth, fine and white in color. Well carved throat with no hint of dewlap. It has a wide back carried horizontal that narrows towards the tail. Strong wings with broad shoulders adhere to the body and cover the back and lie on the tail without crossing each other. The plumage is smooth, shiny, thick, well adherent to the body with large but not soft feathers (AA.VV., 1999; Rubboli \& Mazzanti, 2013).

\section{The Florentine pigeon}

The Florentine is an Italian breed of ornamental pigeons very ancient, but little known (Fig.3); it is very difficult to trace its origin and follow its diffusion in Europe. Already mentioned as a breed in the 1700s, the ancestor of Florentine is a robust pigeon, used for the production of meat, very characteristic for its short and arched shape. $\mathrm{N}$ the modern specimen the head is robust, the neck long, the tail is carried very vertical and divided into two equal halves, the legs are long and robust but the foot is small compared to the overall appearance of the pigeon. The crossing probably with Triganino Modena leads to the current design of the color pattern which is called "gazzo" (an Italian word that remember the magpie and his color pattern), the background color is white, the wing shields are colored, the tail including the wedge and the rump, the head with a mask that starts from the nape of the neck and down 3-4 cm below the beak. In twenty century we approach the current form that is, a robust pigeon, long and straight neck, short and vertical tail. It was widespread in northern Italy, especially in the Alpine area, from this area spread in Austria. The Florentine is bred also in Germany. The most common colors are red, black, brown, blue with or without black rods and yellow (AA.VV., 1999)

\section{The Rondone frill}

The Rondone frill is a very old breed, whose existence is already testified at the beginning of the 19th century (Fig.4); created in the city of Reggio Emilia and surroundings, in all probability through crossings between the Italian Owl and the Damascene pigeon.

There are only two colorations of Rondone frill, the ice with black bars ("lattato" in Italian) and the ice with 
hammered design ("fagiano" in Italian), in both these varieties the background color must be as clear as possible and the neck must not have any grayish or rust tinge. The Rondone frill is a medium-sized pigeon, slightly low on the legs, slender in shape with an inclined standing downwards. The head has a long shape, the neck is full and the upper cranial part is slightly flattened, the forehead is very wide and must form a continuous line with the beak. The eye of the Rondone frill is orange in color while the eyelid and the ocular ring must be black / blue. The beak, black in color, is robust and short, just below the beak there is a well-developed dewlap, in the center of the chest there is an evident frill. The wide and rounded chest is carried slightly raised, while the back and tail are gradually inclined downwards and the tail must never touch the ground (AA.VV., 1999).

\section{The Italian owl}

The Italian owl is an ancient breed created in the city of Reggio Emilia and bred there for centuries (Fig.5); from its homeland of origin this pigeon also derives the name with which it is commonly defined "Reggianino". Its origin can be placed at least around the 16th century. According to some authors, this breed was born from the crossing of neck frill pigeons, of African origin, with local pigeons, perhaps of the Triganino Modena type.

It is a short, taller than long, with small neck frill, weighing about 280/300 grams. Higher on the tarsi than the other breeds of ties, it has a tendency to be on the tip of the toes, horizontal bearing and cubic and angular head. The head must be short and wide, angular, seen in profile and from above it is square in shape since it is flattened in its upper part. The cranial vault tends to be parallel to the midline of the beak. The eyes are bulging, large and bright; located approximately $3 / 5$ forward from the back of the skull, more or less intense orange iris, dark (vetch eye) in white subjects; in the piebald the irises can be both orange and dark but both of the same color. The beak is short, wide at the insertion with the skull, long as wide, straight, it detaches from the forehead forming with it a well marked angle. The throat must have a pronounced dewlap. The plumage is tight-fitting, well adherent to the body, compact. The breed has several well-defined and pure colors (AA.VV., 1999).

\section{The Ascolano pigeon}

The Ascolano pigeon (Fig.6) is the reconstruction of a very ancient breed, of which the first information is found in a 1768 paper; in the painting of 1486, "Annunciation with
Sant'Emidio" by the famous painter Carlo Crivelli, it is represented an ancestor of the modern Ascolano pigeon.(Cantalamessa, 2008).

Its breeding was once widespread not only in the Marche (Central Italy), but also in Emilia-Romagna and Campania. This breed is probably the ancestor of Romagnol.

The Ascolano pigeon is a pigeon with a large conformation, with a wide chest, medium-length body with an inclined bearing downwards, forming a line with the tail, which touches the ground at the tip. Small head in proportion to the structure of the body, smooth and rounded, with long, thin and straight beak. It has an abundant plumage of the body, made up of wide, soft and slightly loose feathers. Sturdy wings and wide wing shield, carried not too close to the body and laid down over the tail without crossing. The legs are medium length, strong and well placed with heavily feathered tarsi and fingers with medium length feathers. The colorations recognized by the standard are black, white, brindle, butterfly and black piebald. The black color must be intense and uniform with the neck rich in beetle green reflections, in the other coats it must have white feathers distributed uniformly on a dark background, and in the piebald the parts of the two colors must have equivalent extensions (AA.VV., 1999).

\section{The Bergamasco pigeon}

Breed created in the countryside of Bergamo in the nineteenth century, probably through crosses between indigenous and Polish pigeons of the English type, in order to obtain subjects that corresponded to the needs of food production for men (Fig.7). This pigeon was widespread in the Bergamo's country land mainly for food use. Its origins are not exactly known, it was mentioned without particular descriptions in the "Picturesque dictionary of natural history and manufactures" by Guèrin in 1845; however, since in the early 1950s, it was present a considerable number of specimens very similar to the modern pigeon.

The Bergamasco pigeon has a very developed red colored eye rings, The back of the head is adorned with a shell tuft, with wide and well developed rosettes, placed low and adherent to the nape and neck (looking at the pigeon in front, both the tuft and the rosettes must not be visible) very thick mane, slanted and long back, thin neck, head with broad forehead, detachment clearly visible between the forehead and the beak, shoulders marked and well delineated from the chest which, although wide, is not prominent. The legs are strong, with a slightly angled profile; bright red tarsi with long fingers. The Bergamasco pigeon has the colors white, black, brown, red, yellow, almond. (AA.VV., 1999; Comi, 2011) 


\section{The Triganino Modena pigeon}

Ancient breed of pigeons, whose origin is supposed to date back to the fifteenth century, the Triganino Modena pigeon (Fig.8) have been bred for many centuries in the city of Modena (Emilia Romagna). Here, until the early 1900s, it was used as a messenger over small and medium distances, but, above all, it was used for a characteristic flight game. It is not possible to establish precisely what its progenitors were but, in all likelihood, it can be said that Triganino was selected through crosses between indigenous pigeons and pigeons of eastern origin, of the type of the current "hen pigeons"; this would also explain the characteristic shape of the Triganino. The name "Triganino" would derive to this pigeon from the speed and grace of its forms that make it resemble a dove ( $\tau \rho v \gamma o ́ v \imath$ in ancient Greek). The Triganino Modena pigeon is a pigeon with an elegant shape and a lively temperament; it has a reduced size, is short, rounded, slender on the high tarsi, well balanced between head and tail; it moves with promptness and agility, has rapid and iridescent flight. Its total length, from the chest to tip of the tail, is about $23 \mathrm{~cm}$. The breed is divided into two large groups of colors: "Schietto" and "Gazzo". The term Schietto derives from the word "sciét", in the Modenese dialect, that means unmixed, pure, in reference to the color of the body, which is totally colored. The Gazzo is so called because of the similarity of its design with that of the Magpie Pica pica (Linnaeus, 1758), "gazza" in Italian. The Gazzo has a white body, with pigmented head, wings, tail and undertail. The dividing line of the colored part, on the nape, should reach the height of the lower contour of the eye. The Triganino Modena pigeon, among all the breeds of pigeons, is certainly the one that includes the most colors; of the Schietto and Gazzo varieties there are over 100 official colors (Polacci, 1978; AA.VV., 1999; Vaccari \& Zambon, 2014).

\section{The Italian beauty Homer}

The breed (Fig.9) was selected from 1980, starting from racing pigeons of above average size, with very developed wattle. It is very similar to a robust muscular, compact race pigeon, with an average erect bearing; it has a rounded head, characterized by well-developed wattles, conical in shape, which increase in volume with the progress of the subject's age. The head appears robust, proportionate to the size of the pigeon, with a gently rounded profile, without interruptions or stapling, from the forehead to the nape it slightly widens towards the rear and continues in the full neck.
The eyes have an iris of a color ranging from bright red to orange, the eye contour is formed by two regular concentric circles, light in color and moderately developed. The beak is strong, well closed, formed by two parts of equal strength, slightly obtuse at the end; the continuation of the beak commissural line must pass through the center of the eye. This breed has well-developed wattles, both seen from the side and from above, they have a triangular shape, they begin shortly after the tip of the beak, gradually rising and widening towards the forehead and ending clearly, detached and higher than the curve of the forehead. In young subjects they have a fine, regular texture and are divided by a longitudinal furrow; in adults they gradually increase in volume, but without forming irregular growths in the two parts of the beak, maintaining their compactness and regular shape. In adults, a light wattle is allowed on the lower part of the beak.

The Italian beauty Homer has various colors and plumage well adheres to the body (AA.VV., 1999).

\section{The Sottobanca pigeon}

The study carried out on the origins of the Sottobanca pigeon traces its creation to the second half of the 1500s in the Modena countryside (Fig.10). The naturalist Ulisse Aldrovandi (1522 - 1605) had several sketches drawn by the painter Jacopo Ligozzi (1547 - 1627) depicting the pigeons raised in the second half of the 1500s, one of which can be traced back to Sottobanca. The name "Sottobanca" seems to derive from the custom of these birds to nest and incubate eggs on the ground, under the tables in the arcades of the rural farmhouses where, in the Modena dialect, the table is called "banca". We can see in this depiction that the Sottobanca had a more or less shellshaped tuft, a relatively short and thick beak compared to all the other pigeons of the time and the shape defined as a boat. Today we can therefore say that the ancestors of the Sottobanca were, already in that time, pigeons that had characteristics very similar to the current Sottobanca, characteristics that have remained unchanged over time. As with all the other indigenous breeds of poultry, the Sottobanca has also undergone the evolution of the times and the transformation of the rural world; today his breeding is almost exclusively aimed at the production of subjects intended for exhibitions, with good typicality and morphologically corresponding to the Breed Standard. This modern kind of selection often penalizes the breeding capacity of specimens.

The Sottobanca is a pigeon rather high on the legs, with proud bearing, horizontal body and slightly raised tail. The head is robust, slightly flattened at the top, with a broad 
and moderately ascending forehead. The back of the head, the nape of the neck, is adorned with a thick shell-shaped tuft. The beak is moderately short, robust, rounded and slightly curved at the tip. The chest is large, prominent, rounded while the back is wide, short and robust, carried as horizontal as possible. (AA.VV., 1999; Garagnani, 2015)

\section{The conservation of the Parma Occhialone pigeon.}

The Parma Occhialone pigeon, an ancient Italian breed, has a history in its own (Fig.11). Today the FIAC, with the involvement of some pigeon breeders, is trying to save this pigeon from extinction. Considered extinct around the mid2000s, in reality the breed has always been bred, albeit with few specimens, by breeders in the Emilia Romagna area.

Particular impetus for the conservation of the breed was given by Mr. Antonino Palazzolo, of Palermo (Sicily), that years ago bought some specimen from a breeder from the northern of Italy and who has preserved the original genetic heritage of this breed over the years.

There are many historical sources that describe this pigeon as early as 1800. In the book "domestic pigeons and breeding" by Alessandro Chigi of 1950, it is reported that the Duchess Maria Amalia of Austria had introduced in Parma, towards the end of the 1700s, many wattle pigeons from Vienna, from which Parma Occhialone pigeons were derived, through crossings with the local Italian Owl and Belgian racing pigeon (Giachetti, 1914; Chigi, 1950).

The breed is still very common in the 70s in Emilia Romagna, so much so that the prestigious specialized magazine "Colombicoltura" dedicates a monograph to the Parma Occhialone pigeon in 1977 (Morini, 1977). The presence of this breed is also evidenced by the participation in national pigeon expositions; until the early eighties the breed was regularly exposed even if with very low numbers, for example in 1979 only 10 specimen of Parma Occhialone pigeon were expose in the national pigeon exposition of Parma (Casadei, 2003).

It is therefore clear that the breed, not being completely extinct, has however continued to persist in many places in northern Italy.

Thanks to the work of Mr. Palazzolo, today the FIAC has created a task force to preserve the genetically characteristics of this breed and spread its breeding.

The Parma Occhialone pigeon is classified in the "barb pigeon" group. Morphologically is a medium - small pigeon, with a slightly inclined posture towards the rear, with a good attitude to flight. It weighs around 400 grams; the tail is about $1,5 \mathrm{~cm}$ longer than the wings.
The head is rather large, high and broad forehead, which joins the beak forming a continuous line; it has a well rounded head, with or without tuft. The beak is on average length, very robust and large, rounded on the tip, fleshcolored. Smooth nasal wattle in the young and in the females, are more developed in the males and in particular in the adult males, of pink color powdered with white. The eyelids are very large and developed, about $6 \mathrm{~mm}$ wide, forming a showy circle (consisting of two three rows of finely granulated rings) of red color. The pigeon has a fairly long, stocky neck with a well-rounded throat. The chest is rounded, not too wide, without a tie. The back is carried sloping and forms a continuous line from the shoulders to the tail. The pigeon has no plumage on legs and plumage well adherent to the body; it is bred in the colors yellow, red, black and white, piebald in all colors (Mc Neillie, 1981).

\section{STATUS AND STRATEGIES FOR CONSERVATION}

For the Italian indigenous breeds, we report below the population estimate obtained from the data collected by breeders registered in the Italian Federation of Pigeons Breeders (Table 1). In the calculation are indicated the pigeons bred by official breeders, a $30 \%$ increase has been added to this number, evaluating an increase due to the percentage of breeders who are not included in FIAC official members. In the case of Triganino Modena pigeon, Italian owl and Florentine, in assessing the population estimate, references was also made to the number of couples raised in other European countries (especially France, Germany and Austria) where these breeds are widespread. The numerical estimate, although not precise for the difficulties of finding information, still allows us to identify the order of magnitude of the existing populations, and to evaluate their conservation status.

For the determination of breeds at risk, reference was made to the criteria reported in "The Global Databank" published by FAO, which classifies domestic breeds into seven categories: extinct, critical, threatened, not at risk, unknown, sustained criticism, sustained threatened (Sherf, 2000).

The categorization is based on the overall size of the population, the number of breeding females and the trend of the size of the population, i.e. whether the population size is increasing, decreasing or stable. If the categorization of a particular breed is at its limit, a further consideration is in the categorization is whether conservation is active and programs for critical or endangered populations are in place. 
The general guidelines used to determine the risk status are as follows; however, the guidelines have been adapted to the biology of the species, which is monogamous (we report the pairs for each breed). In the Table 1 it is also reported the actual trend (if decreasing, stable or growing) for the breeds.

\section{Extinct}

A breed is classified as extinct if the breed population can no longer be easily recreated. This situation remains irreversible and becomes absolute when there are neither breeding males nor breeding females. In reality, extinction can be declared well before the loss of the last animal, gamete or embryo.

\section{Critical}

A breed is classified as critical if the total number of breeding females is less than 100; and therefore, in the case of the pigeons, if the pairs are less than or equal to 100 , being the pigeon a monogamous species.

\section{Threatened}

A breed is classified as endangered (threatened) if the total number of breeding females (or couples for the pigeon) is between 100 and 1000 .

\section{Not at risk}

A breed is classified as "not at risk" if the total number of breeding pairs is greater than 1000 or if it approaches 1000 and is increasing.

\section{Unknown}

It is a category reserved for breeds of which numerical data relating to the individuals are not known. In this category we could find all the previous categories, but we are not able to define their status.

Domestic breeds can be further classified as critical supported and threatened - supported; these categories identify populations with critical or endangered status for which conservation programs are active (both managed by private and public companies).
Table 1. Population size and status for Italian authocthonous breeds.

\begin{tabular}{|c|c|c|c|}
\hline Breed & $\begin{array}{l}\text { Population } \\
\text { estimate } \\
\text { (expressed in } \\
\text { pairs) }\end{array}$ & Status & Trend \\
\hline $\begin{array}{l}\text { Ascolano } \\
\text { pigeon }\end{array}$ & 200 & Threatened & Stable \\
\hline Bergamasco & 350 & Threatened & Stable \\
\hline Italian Owl & $>1000$ & Not at risk & Growing \\
\hline Rondone frill & 80 & $\begin{array}{l}\text { Critical - } \\
\text { supported }\end{array}$ & Growing \\
\hline Florentine & 650 & Threatened & Stable \\
\hline $\begin{array}{l}\text { Parma } \\
\text { Occhialone } \\
\text { pigeon }\end{array}$ & 55 & $\begin{array}{l}\text { Critical - } \\
\text { supported }\end{array}$ & Growing \\
\hline Piacentino & 325 & Threatened & Decreasing \\
\hline Romagnol & 800 & Threatened & Decreasing \\
\hline Sottobanca & 120 & Threatened & Decreasing \\
\hline $\begin{array}{l}\text { Triganino } \\
\text { Modena }\end{array}$ & $>1000$ & Not at risk & Growing \\
\hline $\begin{array}{l}\text { Italian beauty } \\
\text { Homer }\end{array}$ & $>1000$ & Not at risk & Growing \\
\hline
\end{tabular}

\section{CONCLUSION}

Of the Italian autochthonous breeds, the Italian Owl, the Triganino Modena and the Italian beauty Homer are certainly three out of risk breeds without problems for their future conservation. The Rondone frill and the Parma Occhialone pigeon are now present with numbers that classify them in the "critical" category. For the Rondone frill a numerical increase program is being developed, for the Parma Occhialone pigeon the FIAC has activated a recovery and diffusion program.

For the three typical breeds of Emilia Romagna Sottobanca, Piacentino and Romagnol we have defined a threatened status; their situation is worrying because of the decreasing trend.

Also for the breeds of Ascolano pigeon, Bergamasco and Florentine there is a worrying situation because their populations are represented by a few hundred couples (threatened category) and their populations are stable and not growing.

In conclusion, it seems clear to the Author that the Italian Pigeon Breeders Federation - FIAC and its numerous 
breeders have preserved the biodiversity heritage of the domestic pigeon in Italy. Today the conservation of these breeds is certainly more difficult for many factors, especially in the average age of breeders, around 60 years, and the lack of new and young breeders.

Raising pigeons today is very difficult in Italy, because of the current health regulations that impose many restrictions.

The work started and continued by the Italian pigeon breeders will probably have to be encouraged in order to lead, in the coming years, to a numerical increase in all breeds, to guarantee a future for domestic biodiversity of this interesting species.

\section{ACKNOWLEDGEMENTS}

The Author is grateful to Tiziano Trinci and Filippo Bartoletti for the contribution given to the realization of the work.

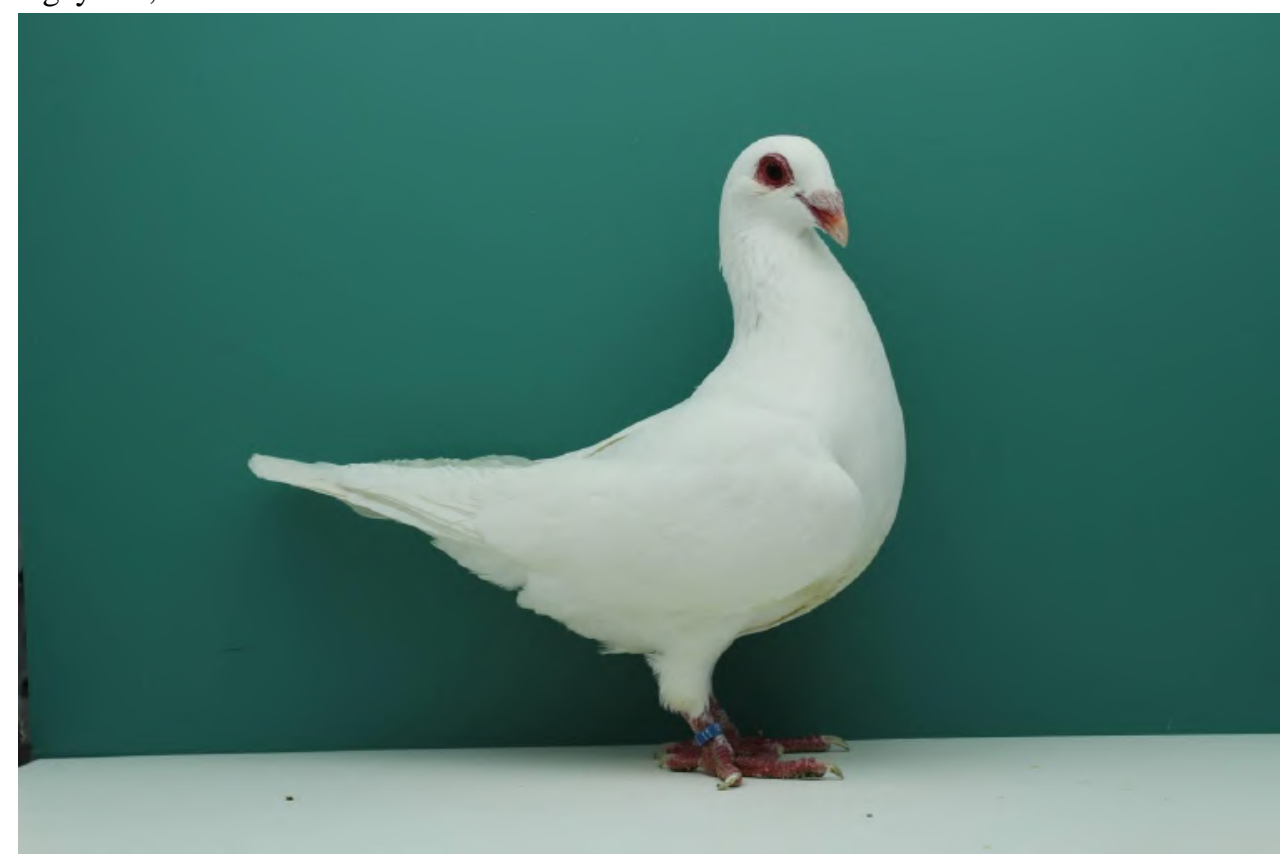

Fig.1: The Piacentino pigeon (Photo by R. Comi-FIAC)

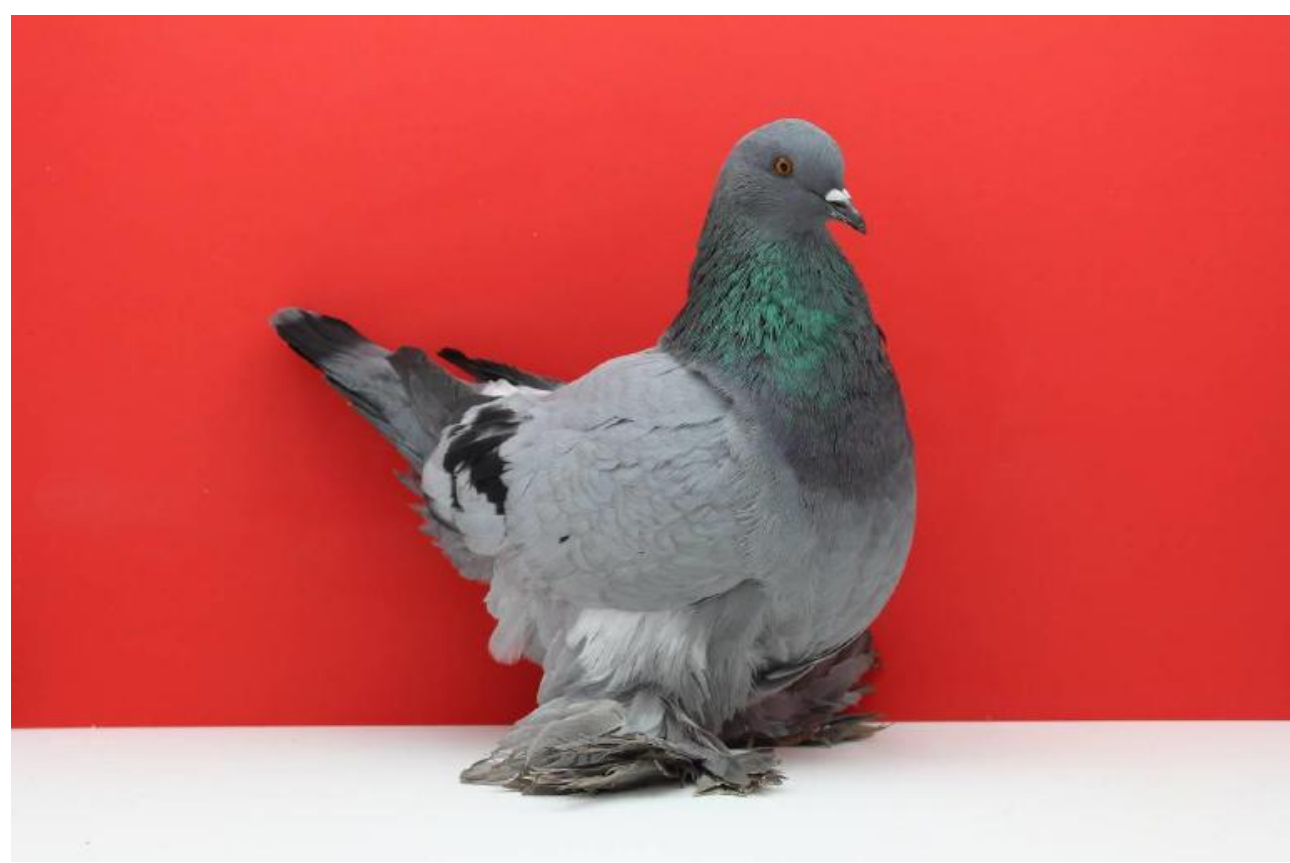

Fig.2: The Romagnol pigeon (Photo by R. Comi-FIAC) 
International Journal of Environment, Agriculture and Biotechnology, 5(2)

Available: https://ijeab.com/

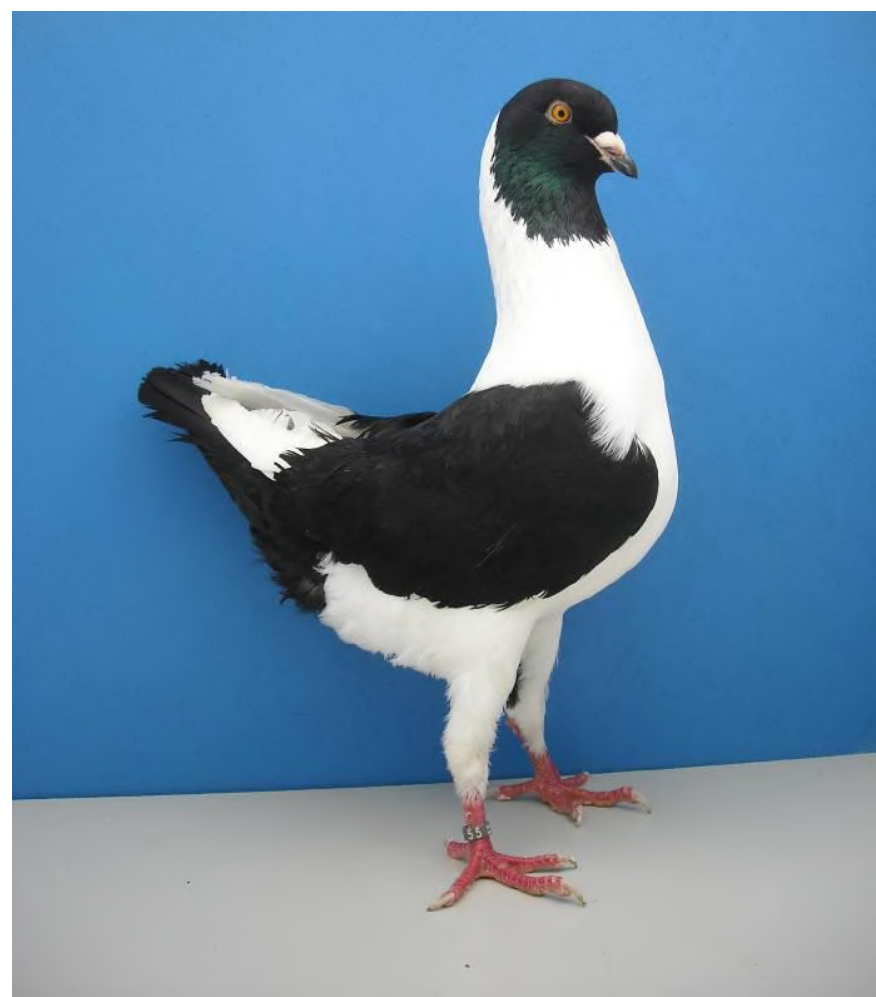

Fig.3: The Florentine pigeon (Photo by R. Comi-FIAC)

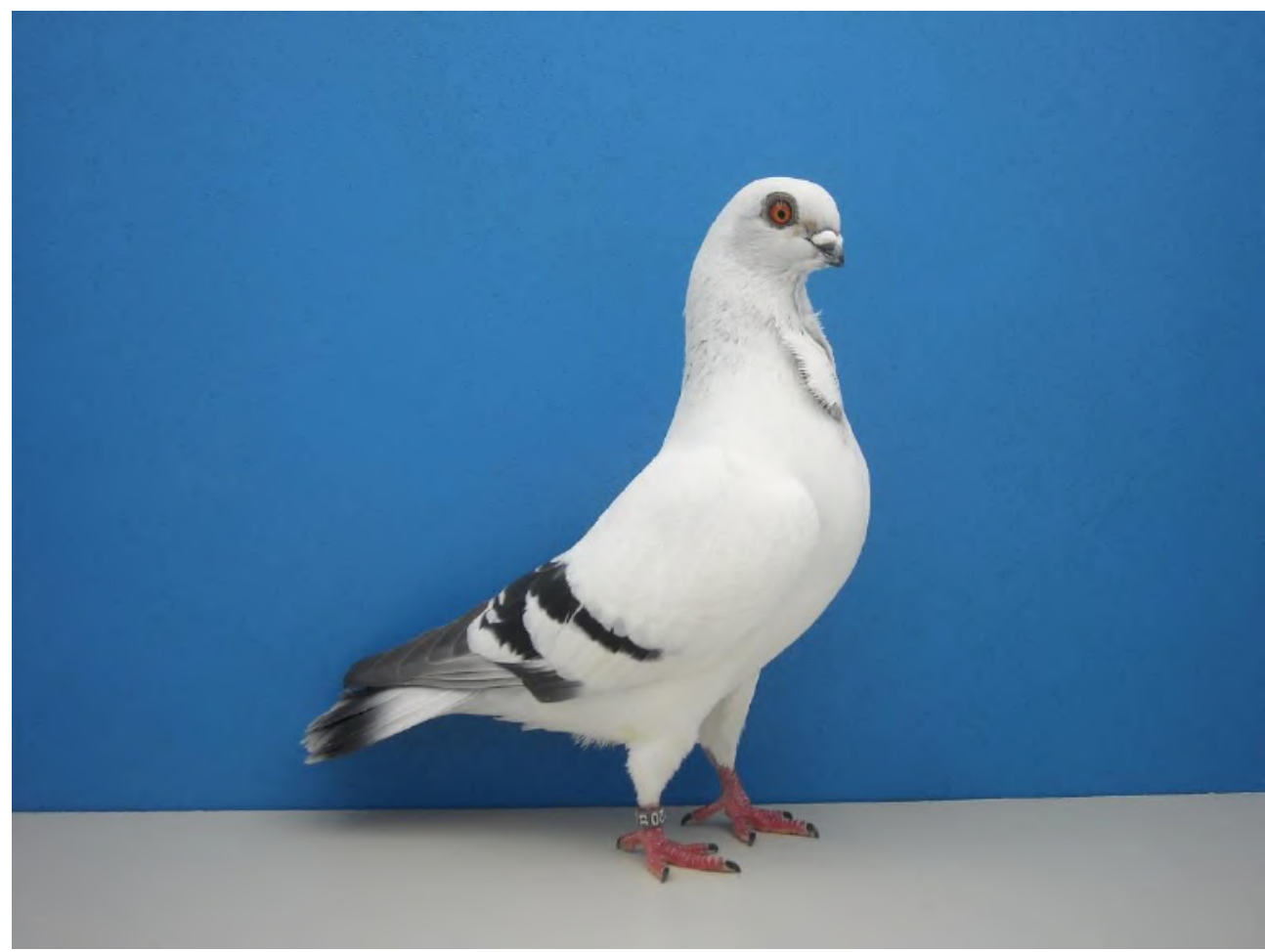

Fig.4: The Rondone frill (Photo by R. Comi-FIAC) 
International Journal of Environment, Agriculture and Biotechnology, 5(2)

Available: https://ijeab.com/

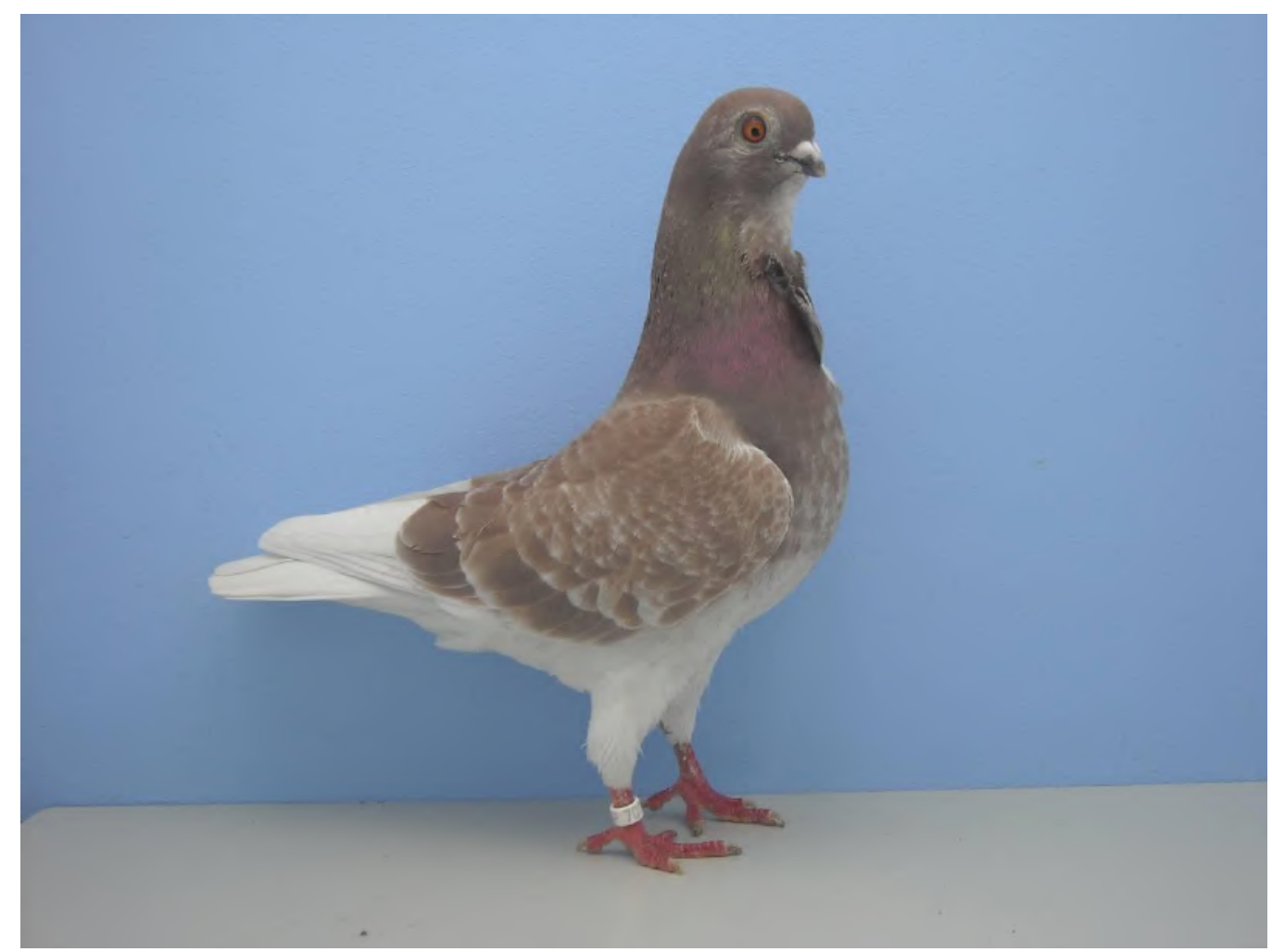

Fig.5. The Italian owl (Photo by R. Comi-FIAC)

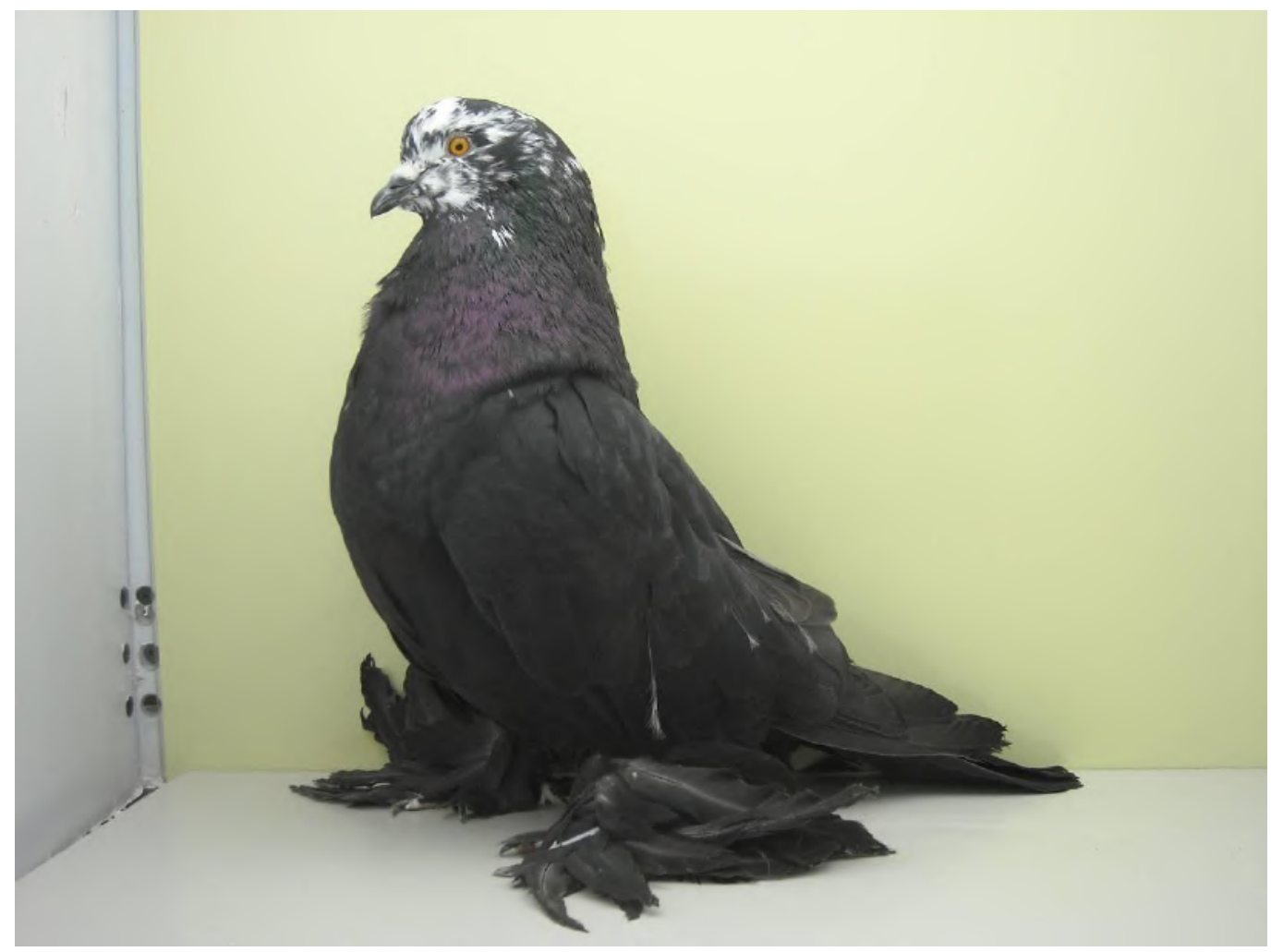

Fig.6: The Ascolano pigeon (Photo by R. Comi - FIAC) 
International Journal of Environment, Agriculture and Biotechnology, 5(2)

Available: https://ijeab.com/

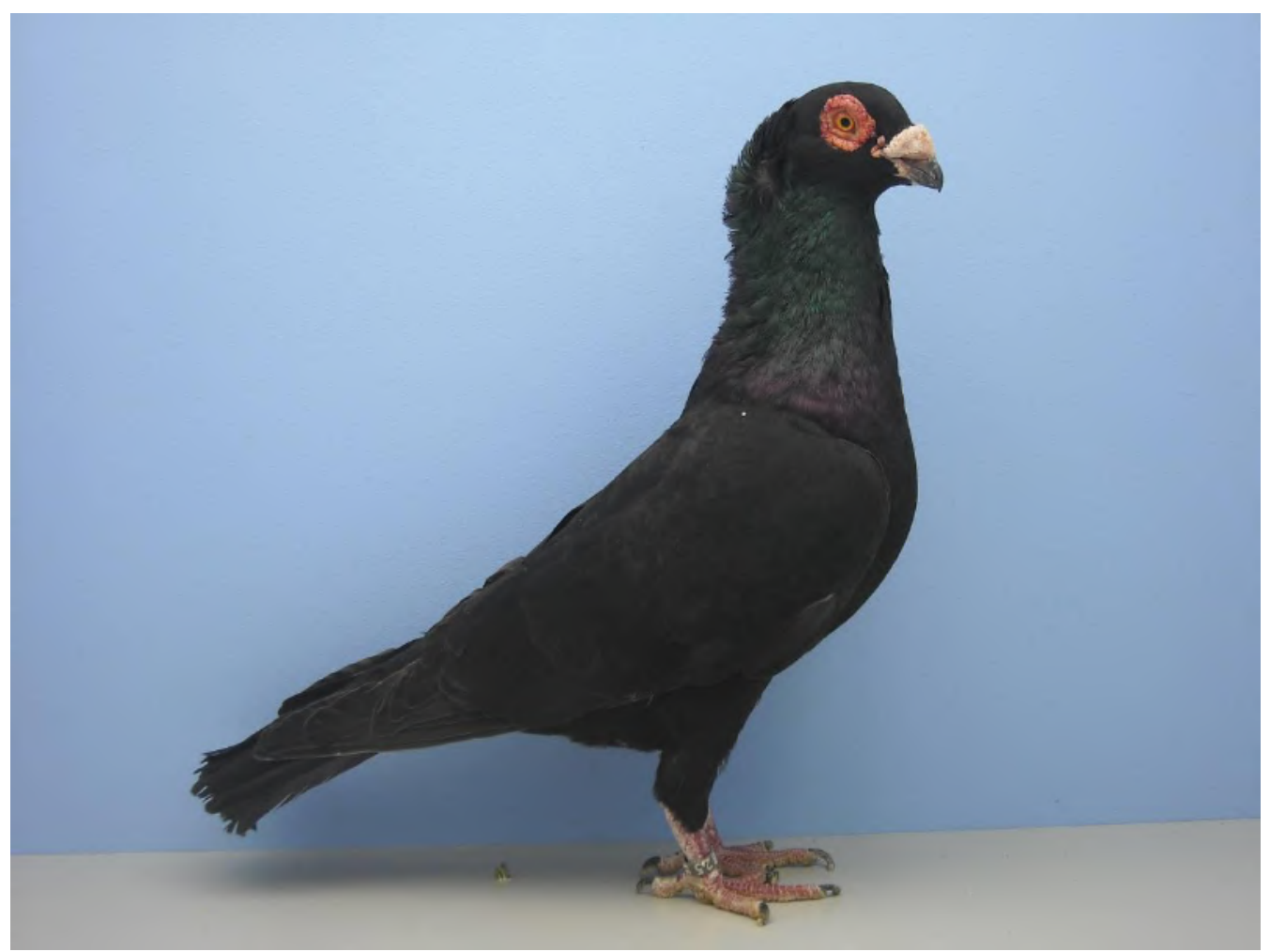

Fig.7: The Bergamasco pigeon (Photo by R. Comi-FIAC)

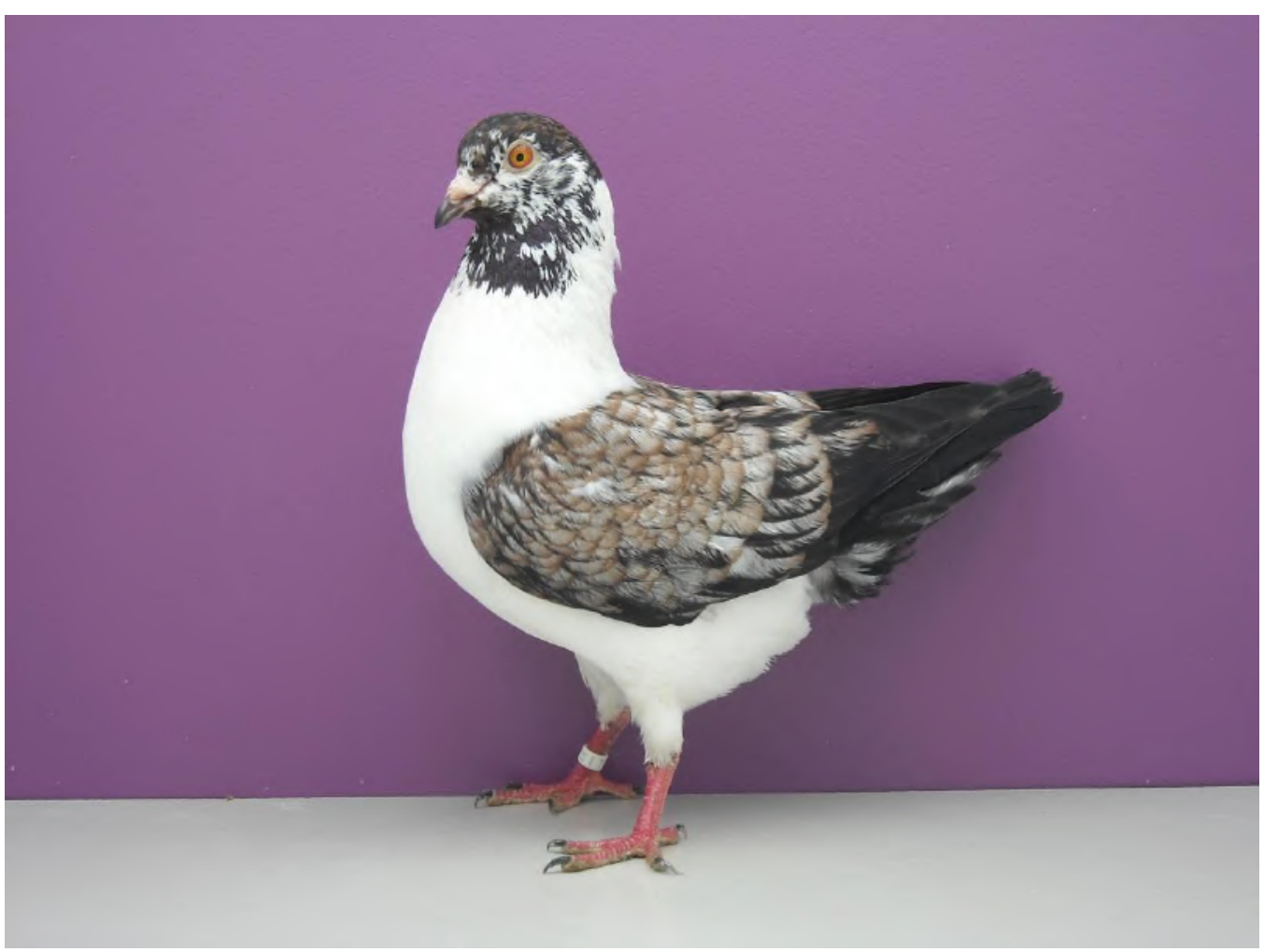

Fig.8: The Triganino Modena pigeon (Photo by R. Comi-FIAC) 
International Journal of Environment, Agriculture and Biotechnology, 5(2)

Available: https://ijeab.com/

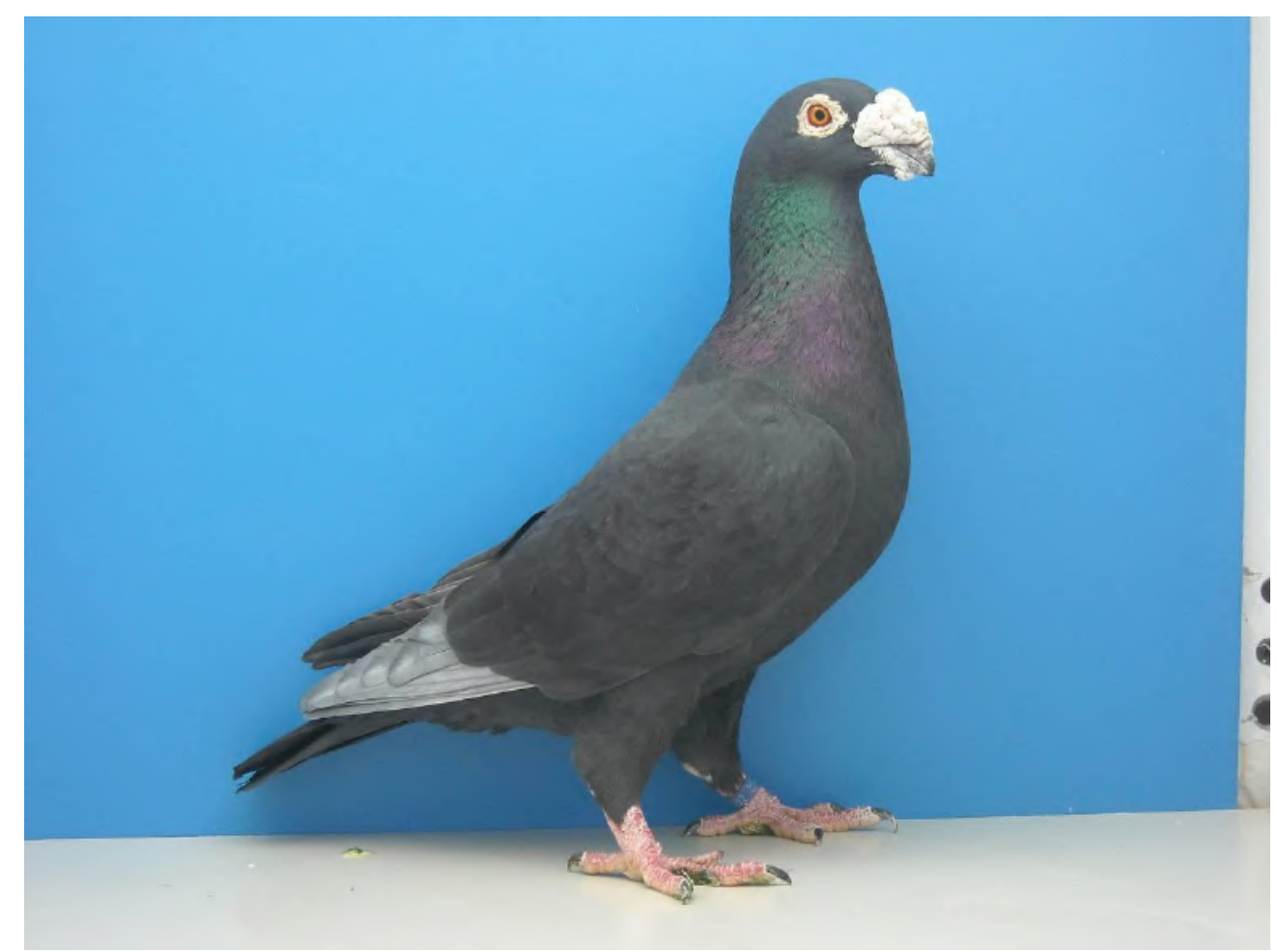

Fig.9: The Italian beauty Homer (Photo by R. Comi - FIAC)

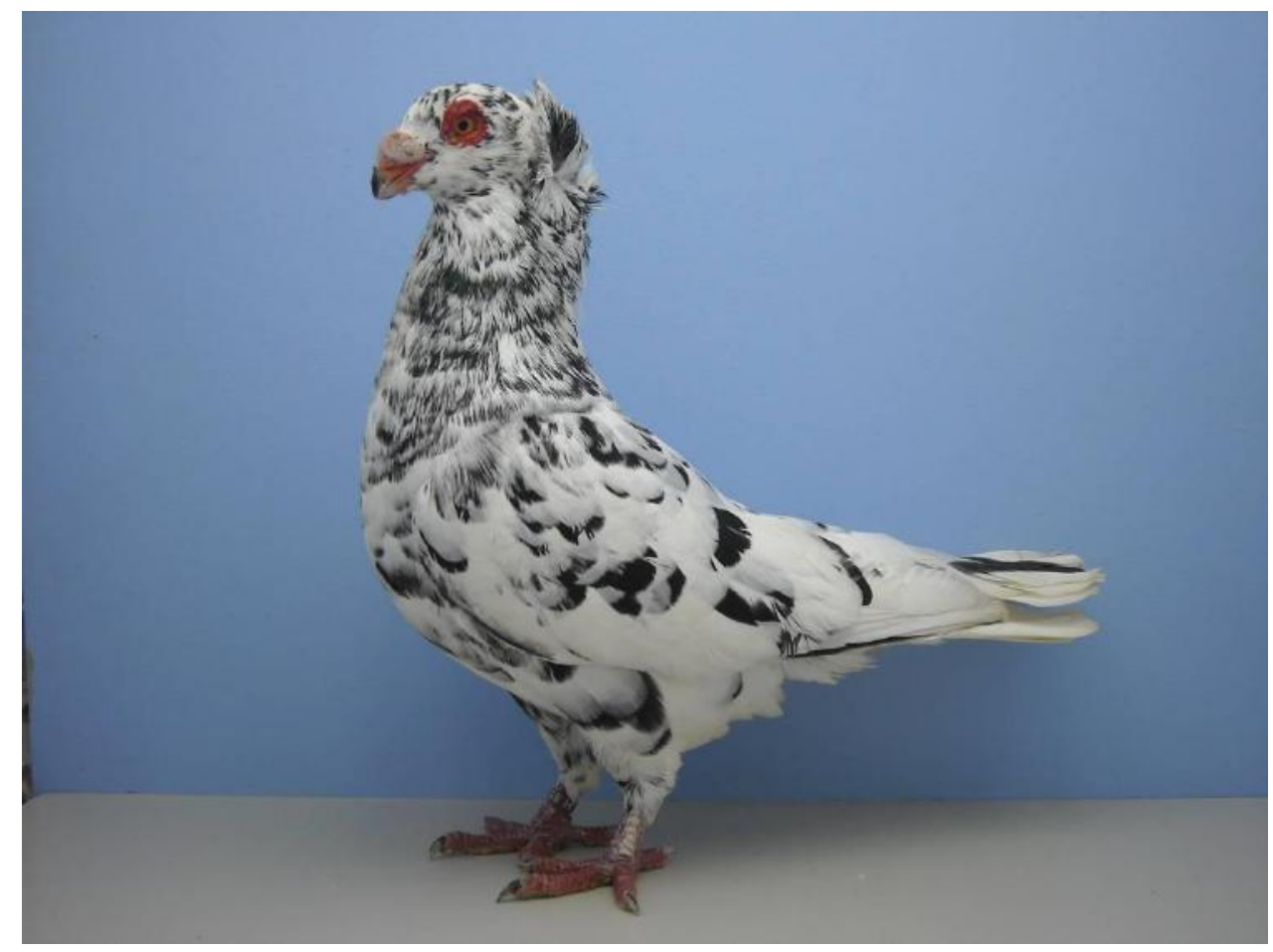

Fig.10: The Sottobanca pigeon (Photo by R. Comi - FIAC) 


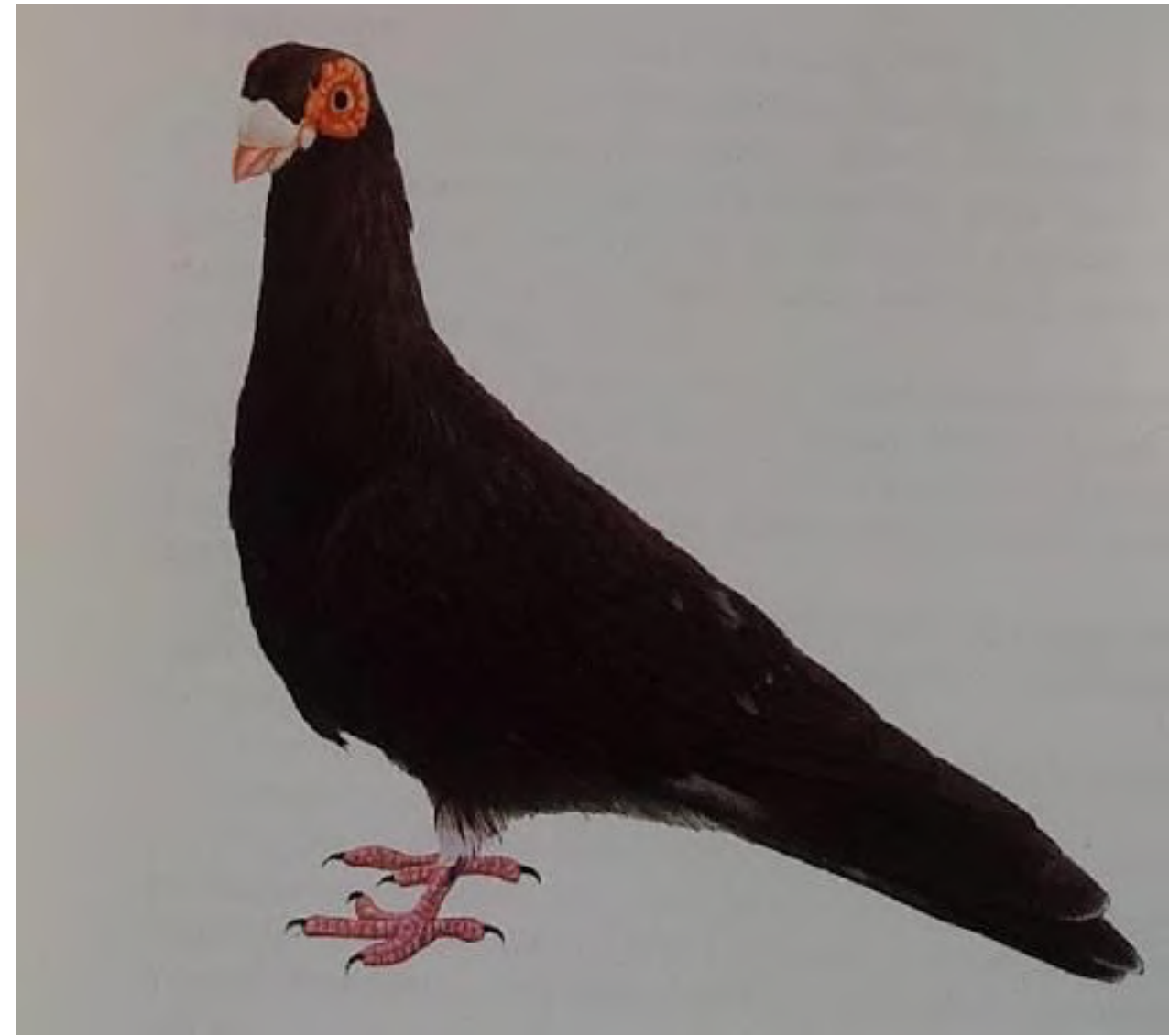

Fig.11: The Parma Occhialone pigeon (Imagine by Mc Neillie A., 1981)

\section{REFERENCES}

[1] AA. VV., 1999. Standard delle razze dei colombi. FIAC Federazione Italiana Allevatori di Colombi.

[2] AA. VV., 2018. EE-List of the breeds of fancy pigeons ELFP. Section for Fancy pigeons of the European Association of Poultry, Pigeon and Rabbit breeders (Entente Européenne d' Áviculture et de Cuniculture)

[3] Belew, A.K., Tesfaye, K and Belay, G. 2016. The state of conservation of animal genetic resources in developing countries: A review. Int. J. Pharma. Med. Biol. Sci., 5(1): 5866.

[4] Bigi, D. \& Zanon, A. 2008. Atlante delle razze autoctone. Edagricole.

[5] Calzecchi Onesti R. (a cura di), 1977. Columella Lucio Giunio Moderato - L'arte dell'agricoltura [De re rustica] . Einaudi Editore.

[6] Cantalamessa A. G., 2008. Il colombo ascolano. Opuscolo Informativo. ACAP Associazione Colombofila Allevatori Piceni.

[7] Casadei L., 2003. Comunicazioni brevi. Notiziario della Federazione Italiana Allevatori di Colombi: Anno XXV $\mathrm{n}^{\circ} 102$.

[8] Chigi A., 1950. Piccioni domestici e colombicoltura. Reda Editore

[9] Comi R., 2011. Il bergamasco. Notiziario della Federazione Italiana Allevatori di Colombi: Anno I $-\mathrm{n}^{\circ} 4$.
[10] Giachetti G.C., 1914. Monografia dei piccioni domestici. Battiato Editore.

[11] Giusti F., 1996. La nascita dell'agricoltura: aree, tipologie e modelli. Donzelli Editore,

[12] Grunenfelder, H.P. , 2001. Risorse genetiche agrarie in Italia. Monitoring Institute for Rare Breeds and Seed in Europe.

[13] Hanotte, O. \& Jianlin, Han., 2005. Genetic characterization of livestock populations and its use in conservation decision making. The role of biothecnology congress, Turin, $5-7$ March 2005

[14] Garagnani U., 2015. Il colombo Sottobanca. Multigrafica Vignola (MO)

[15] Malossini F., 2011. Gli allevamenti animali nel fondo rustico dell'antica Roma. Atti Acc. Rov. Agiati, a. 261, ser. IX, vol. I.

[16] Mc Neillie A., 1981. Colombi: atlante delle razze. Edagricole.

[17] Morini S., 1977. I Parmigiani o Occhialoni di Parma. Colombicoltura ${ }^{\circ} 1$ del 1977

[18] Pietro Puliatti (a cura di), 1989. Alessandro Tassoni - La secchia rapita e scritti poetici. Panini.

[19] Pizzuti Piccoli A., 2011. I colombofili come moderni Noè nelle loro colombaie Arca. Notiziario della Federazione Italiana Allevatori di Colombi: Anno I - ${ }^{\circ} 3$.

[20] Pizzuti Piccoli A., 2016. Colombi ornamentali $e$ colombicoltura. Alcedo Ornitologia e Natura: Vol. 90. 
[21] Polacci C., 1978. Il colombo triganino. Banco San Gemignano e San Prospero.

[22] Rischkowsky B. \& Pilling D, (Eds), 2007. The state of the world's animal genetic resources for food and agriculture. FAO Food and Agriculture Organization of the United Nations, Rome, Italy.

[23] Rubboli R. \& Mazzanti G., 2013. Il Colombo Romagnolo. Associazione Colombofila Ravennate.

[24] Shah, R.R., Pandey, D.P. \& Panchasara, H.H., 2016. Biodiversity in domestic animals: Threats and action plans. In: Livestock production under diverse constraints. Sastry, N.S.R., 1st Ed., Write and Print Publications, New Delhi, pp. 62-72.

[25] Sherf B. D., 2000. World watch list for domestic animal diversity. 3rd Ed. FAO Food and Agriculture Organization of the United Nations, Rome, Italy.

[26] Traglia A. (a cura di), 1996. Varrone Marco Terenzio - Il fondo rustico. UTET

[27] Vaccari A. \& Zambon F., 2014. La storia del triganino modenese. Notiziario della Federazione Italiana Allevatori di Colombi: Anno IV - n 14 